ARTÍCULO

\title{
LA ÉPOCA DE LOS DESCUBRIMIENTOS Y CONQUISTAS DE ULTRAMAR TÉRMINO DE LA HISTORIA DE PORTUGAL DE ALEXANDRE HERCULANO, COMIENZO DE LA HISTORIA DE MÉXICO DE LUCAS ALAMÁN*
}

\author{
THE AGE OF OVERSEAS DISCOVERIES AND CONQUESTS
}

\begin{abstract}
ALEXANDRE HERCULANO'S HISTORIA DE PORTUGAL TERMINATION, AND LUCAS ALAMAN'S HISTORIA DE MÉXICO BEGINNING
\end{abstract}

\author{
Ricardo Ledesma Alonso \\ Universidad Nacional Autónoma de México \\ Instituto de Investigaciones Filológicas \\ Becario posdoctoral \\ ricardoledesmaalonso@comunidad.unam.mx
}

\begin{abstract}
Resumen
Este artículo tiene el propósito de contribuir a la discusión crítica sobre las características genéricas de la historiografía nacional escrita en los ámbitos europeo y americano durante el siglo XIX. Como hipótesis sugiero que, a través de los componentes de su estructura narrativa, la historiografía nacional simbolizó los ideales de constitución política del Estado-nación sustentados por sus autores. Para desarrollar esta proposición planteo un estudio comparativo de las historias nacionales de Portugal y de México compuestas, respectivamente, por Alexandre Herculano (1810-1877) y Lucas Alamán (1792-1853). El análisis del lugar narrativo de término o comienzo asignado, en cada caso, al mismo acontecimiento de las conquistas y descubrimientos de ultramar, revelará los presupuestos ideológicos implícitos en las decisiones narrativas de este par de historiadores de la nación.
\end{abstract}

Palabras clave: historiografía portuguesa siglo XIX; historiografía mexicana siglo XIX; historiografía nacional; estrategias narrativas; municipalismo.

\begin{abstract}
This article is aimed to contribute to the critical discussion about the general features of national historiographies written in Europe and America during the 19th century. As a hypothesis, I suggest that national historiography symbolizes the authors' ideals of the political constitution of the nation state through their respective narrative components. In developing this approach, I make a comparative study of both national histories of Portugal and Mexico, respectively written by Alexandre Herculano (1810-1877) and Lucas Alamán (17921853). The analysis of the narrative place of "termination" or "beginning" assigned in each case to a "same" event -the conquests and overseas discoveries" - will reveal the ideological presuppositions implicit in the narrative decisions of both authors.
\end{abstract}

* Becario del programa de becas posdoctorales en la Universidad Nacional Autónoma de México (unam), Instituto de Investigaciones Filológicas, asesorado por la doctora Aurora Díez-Canedo Flores. 
Keywords: 19th century Portuguese historiography; national historiography; narrative strategies; municipalism.

Información del artículo

Recibido: 25 de septiembre de 2019.

Aceptado: 27 de marzo de 2020.

DOI: $10.22201 /$ iih.24485004e.2020.59.70925

\section{Introducción}

A lo largo del siglo xIx, las sociedades europeas y americanas atravesaron por un conjunto de procesos que condujeron al surgimiento y consolidación de los estados nacionales. ${ }^{1}$ Como ha sido señalado por numerosos especialistas, la escritura de la historia, convertida por entonces en una disciplina profesional practicada y enseñada en las universidades del Viejo y el Nuevo Mundos - es decir, en una ciencia con principios heurísticos y hermenéuticos bien establecidos-, participó activamente en la construcción de esa inédita realidad socio-política. ${ }^{2}$ En una faceta que quizá pocos le conocen -a causa de la imagen distorsionada que priva de él como un historiador ocupado exclusivamente de minucias documentales-, Leopold von Ranke sintetizó, mejor que ningún otro autor de su tiempo, la encomienda pragmática que el mundo posrevolucionario confirió a la historiografía científica:

Por consiguiente, la historia tiene el cometido de determinar la naturaleza del Estado, partiendo para este fin de los acontecimientos del pasado y de difundir esto; a la política le corresponde desarrollar y llevar a cabo la misión histórica, una vez que ésta haya sido comprendida y reconocida como tal. ${ }^{3}$

${ }^{1}$ Eric Hobsbawm, Naciones y nacionalismo desde 1780 (Barcelona: Crítica, 2012); Ernest Gellner, Nations and Nationalism (Nueva York: Blackwell Publishing, 2006); Benedict Anderson, Comunidades imaginadas. Reflexiones sobre el origen y la difusión del nacionalismo (México: Fondo de Cultura Económica, 1993).

${ }^{2}$ Stefan Berger, Mark Donovan y Kevin Passmore, Writing National Histories. Western Europe Since 1800 (Nueva York: Routledge, 1999), 3-4; Alexander Betancourt Mendieta, América Latina: cultura letrada y escritura de la historia (México: Anthropos; Universidad Autónoma de San Luis Potosí, Facultad de Ciencias Sociales y Humanidades, 2018), 11.

${ }^{3}$ Leopold von Ranke, "Über die Verwandschaft und den Unterschied des Historie und der Politik”, en Sämtiliche Werke, v. 24 (Leipzig: Duncker und Humblot, 1872), 288; Frank Ankersmit, La experiencia histórica sublime (México: Universidad Iberoamericana, 2010), 338. 
Reconocer y comprender la misión histórica del Estado-nación era, según afirmaba el autor prusiano, la tarea fundamental del historiador. A este último le incumbía sentar las bases teóricas que al político —quien, en la mayor parte de los casos, era la misma persona que el historiador-correspondía desarrollar en la vida social.

Ahora, para llevar a cabo su cometido, el estudioso de la historia debía hacer una inmersión crítica en el pasado remoto a través del estudio de aquellos monumentos donde existiera algún indicio del origen y la misión de las naciones modernas. ${ }^{4}$ Una vez realizada dicha labor, tenía por encargo exponer sus descubrimientos en una narración coherente de la historia vital de la nación. A este respecto, importa señalar que, no obstante sus fundamentos documentales, esa suerte de biografía de la nación no estaba desprovista de un sustrato ideológico; ${ }^{5}$ hecho que resulta más que eviden-

${ }^{4}$ Francisco Vázquez García, Estudios de teoría y metodología del saber histórico (Cádiz: Universidad de Cádiz, Servicio de Publicaciones, 1989), 27-43. Como puede inferirse de estos señalamientos, la búsqueda del origen y destino históricos de las naciones fue una empresa extremadamente sofisticada y compleja. En principio, no es secundario subrayar que, para llevarla a cabo, los historiadores nacionalistas pusieron a su servicio todas las herramientas del método crítico depuradas por la profesionalización de la escritura de la historia. Vázquez García, Estudios de teoría y metodología..., 63-68. En tanto que los monarcas por derecho divino y sus historias fundadas en el milagro o en una verdad revelada a algunos cuantos elegidos habían sido desacreditados por los movimientos revolucionarios de finales del siglo XVIII, el recurso al ámbito de lo trascendental resultaba ahora obsoleto para la escritura de la historia. De ahí se sigue que los historiadores profesionales/nacionalistas hicieran de lo real, es decir, del ámbito de lo inmanente, lo concreto y lo histórico - que para ellos no era otra cosa que lo científico e intersubjetivamente comprobable a partir de la evidencia documental- uno de los pilares principales de su actividad. Jacques Rancière, Les mots de l'histoire. Essai de poétique du savoir (Lonrai: Éditions du Seuil, 1992), 9-10; Frank Ankersmit, Historia y antropología. Ascenso y caída de la metáfora (México: Fondo de Cultura Económica, 2004), 151-190; Patrick J. Geary, The Myth of Nations. The Medieval Origins of Europe (Nueva Jersey: Princeton University Press, 2002), 32. Esto último queda ilustrado por las afirmaciones que a este respecto formularon dos de los más importantes historiadores de las naciones del siglo XIX, me refiero a Wilhelm von Humboldt y Leopold von Ranke, quienes sostuvieron que, antes que nada, el historiador de la nación debía abocarse a la investigación "exacta [documental], imparcial y crítica de lo sucedido". Por otro lado, merece ser resaltado que estos mismos historiadores razonaron que había algo del pasado que escapaba a su "observación directa"; algo que debía más bien "intuir" o "imaginar" el sujeto congnoscente. Aquello que precisaba ser "imaginado" era la "unidad esencial", el conjunto de "íntimos nexos causales" que constituía la "verdad interior" de los acontecimientos: el "carácter nacional". Frank Ankersmit, Narrative Logic (La Haya: Martinus Nijhoff Publishers, 1983), 122-123.

${ }^{5}$ En este artículo entenderé por ideología al conjunto de creencias o preferencias políticas que subyacen al pensamiento de un individuo o de un conjunto de individuos, el cual guía sus actividades políticas y expresa, tácita o explícitamente, las luchas de intereses opuestos 
te en las numerosas versiones de la historia nacional que aparecieron en el seno de las distintas sociedades occidentales decimonónicas. Por tal razón, juzgo que más que narrar y legitimar el ascenso, en abstracto, del Estado-nación, las mencionadas historias buscaron proponer, acompañar y justificar proyectos específicos de constitución del Estado-nación: proyectos monárquicos o republicanos, centralistas o federalistas, liberales o conservadores, étnicos o políticos.

Con el objetivo de discutir el carácter narrativo e ideológico de la historiografía nacional decimonónica, en el presente artículo se ensayará un análisis crítico de las respectivas historias nacionales de Portugal y de México de Alexandre Herculano de Carvalho e Araújo (1810-1877) y de Lucas Alamán (1799-1853). ${ }^{6}$ La decisión de analizar el pensamiento histórico de estos autores no es en ningún sentido gratuita. Por el contrario, se puede justificar aduciendo varios argumentos. En primer lugar, que estos historiadores no sólo fueron contemporáneos, sino que redactaron sus principales trabajos casi de manera simultánea, durante las décadas de 1840 y 1850. En segundo, que los especialistas han valorado sus historias nacionales como las de mayor calidad crítica, mayor coherencia y mayor alcance interpretativo, en el marco de sus correspondientes horizontes de enunciación. En tercero, que a pesar de ser historiadores a los cuales podría caracterizarse como periféricos en relación con el paradigma historiográfico - heurístico y hermenéutico- del norte de Europa, esa condición no los privó de participar, a través de postulados en extremo originales, en los debates teóricos, metodológicos, narrativos e ideológicos propios de la historiografía nacional decimonónica. Y en cuarto, que si bien ninguno tuvo jamás noticia de la actividad historiadora del otro, ambos llegaron a conclusiones similares sobre la naturaleza del Estado-nación en el mundo ibérico e iberoamericano.

Por último, debo señalar que además de percibir las mencionadas semejanzas, considero que el hecho de que Herculano y Alamán convinieran en hacer del mismo momento histórico un punto clave de sus narraciones

y los arreglos institucionales de las clases sociales y partidos que integran a una sociedad. Joshua Simon, The Ideology of Creole Revolution. Imperialism and Independence in American and Latin American Political Thought (Nueva York: Columbia University Press, 2017), 18-20.

${ }^{6}$ Conviene precisar que, en el caso de Herculano, por historia nacional de Portugal aludiré al conjunto narrativo conformado por las Cartas sobre a história de Portugal (1842), la História de Portugal (1846-1853) y la História da Origem e Estabelecimento da Inquisição em Portugal (1853-1859); mientras que, para el caso de Alamán, comprenderé a su historia nacional de México como la unidad de sentido constituida por sus Disertaciones sobre la historia de la República mexicana (1844-1849) y su Historia de México (1849-1852). 
sobre la historia nacional - hablo de la época de los descubrimientos y conquistas de ultramar emprendidos por las sociedades ibéricas (siglos $\mathrm{XV}$ y xVI) - abre una oportunidad de oro para discutir, teoréticamente, la relación entre las decisiones narrativas de los historiadores nacionalistas y sus principios ideológicos.

Origen y destino históricos: el código de la historiografía nacional decimonónica

Al final de su ensayo La nación como problema, Elías Palti propone entender la historiografía nacional decimonónica como una "ficción de identidad". Tal caracterización pretende destacar que ese tipo de discursos tuvo por cometido "llenar simbólicamente", hacer inteligible y significativo el "vacío originario constitutivo" de la fundación institucional del Estado-nación moderno. ${ }^{7}$ Ahora, como contribución al argumento del crítico argentino, quisiera tan sólo especificar - siguiendo en esto a Benedict Anderson- que la historiografía nacional desarrolló la referida función simbólica a partir de un radical encubrimiento: configuró "imágenes" o "ficciones" de la "antigüedad subjetiva" y el "futuro ilimitado" de las naciones en aras de ocultar su "novedad", "contingencia” y "modernidad objetiva[s]". ${ }^{8}$ Desde mi perspectiva, dicho encubrimiento se encuentra directamente relacionado con la necesidad experimentada por los historiadores nacionalistas de dar dirección y legitimidad, sentido histórico, al nuevo orden político y social emanado de las revoluciones que propiciaron la caída del Antiguo Régimen. Para justificar su presente, para fundarlo sobre principios menos contingentes que los azares de las guerras y las revoluciones de los que objetivamente había nacido, ${ }^{9}$ las élites políticas ascendidas a los gobiernos de las sociedades europeas y americanas precisaron de imaginar dos puntos en el tiempo a partir de los cuales conferir sentido a sus acciones: un comienzo, origen o incipit de sus sociedades en el pasado remoto, y un final, telos o excipit hacia el cual dirigirlas. Estos dos puntos constituyeron, básicamente, el marco narrativo fundamental de la historiografía nacional

${ }^{7}$ Elías Palti, La nación como problema. Los historiadores y la "cuestión nacional" (Buenos Aires: Fondo de Cultura Económica, 2003), 145-146.

${ }^{8}$ Anderson, Comunidades imaginadas..., 15-22.

${ }^{9}$ Palti, La nación como problema..., 131. 
-las fronteras entre las cuales la mera cronología y el azar se transformaban en destino nacional.

Ahora bien, sobre los comienzos y los finales de la historiografía nacional no resultará exagerado convenir en que se trata de fenómenos que pertenecen más al ámbito de la ficción o la imaginación que al del razonamiento crítico. Desde la década de los sesenta del siglo xx, Frank Kermode, Louis O. Mink, Hayden White y Paul Ricoeur, entre otros tantos críticos, han venido afirmando que la historiografía participa de una conciencia poética creadora de ficciones o patrones coherentes. La historia, al igual que la literatura, impone una trama al tiempo, le confiere "una organización que humaniza el tiempo al darle forma”. Escribir historia no significa abocarse al mero registro de hechos sin otra liga que la mera sucesión cronológica; por el contrario, se trata de imponerle una forma, una trama que vuelva inteligibles hechos discontinuos y contingentes al configurarlos como partes mutuamente implicadas y condicionadas en un continuum significativo, en una duración. ${ }^{10}$ Con base en esta premisa, me atrevo aquí a plantear como hipótesis de trabajo que los comienzos y los finales de las obras de historiografía nacional son ficciones que encarnan los intereses y las decisiones tanto estéticas como ideológicas de quien las escribió y de los contextos intelectuales en que aparecieron. ${ }^{11}$

En cuanto a la primera de las marcas narrativas de la historiografía nacional, el comienzo, es preciso subrayar que no puede ni debe ser considerado como una frontera natural, quiero decir, como un límite que pertenece al orden natural de la realidad. La designación de un punto en el tiempo y en el espacio como origen del Estado-nación y como punto de partida de la narración sobre el mismo es un acto violento y artificial, jamás natural. Violento porque, como sostiene el crítico Andrea del Lungo, todo acto inaugural de toma de palabra implica la imposición arbitraria de una frontera entre un nuevo mundo discursivo y otros mundos discursivos e histórico-sociales; ${ }^{12}$ y artificial, porque cualquier comienzo —en palabras de Edward Said- es una "ficción necesaria", es decir, una construcción

${ }^{10}$ Frank Kermode, The Sense of an Ending. Studies in the Theory of Fiction (Nueva York: Oxford University Press, 1968), 43-45, 56-57; Luis O. Mink, Historical Understanding (Ithaca: Cornell University Press, 1987), 47-48, 60; Hayden White, The Content of the Form: Narrative Discourse and Historical Representation (Baltimore: Johns Hopkins University, 1987), 9; Paul Ricoeur, Temps et récit, v. 1 (Lonrai: Éditions du Seuil, 1983), 128-129.

${ }^{11}$ Kermode, The Sense of an Ending..., 3-37, 45.

12 Andrea del Lungo, L'incipit romanesque (París: Éditions du Seuil, 2003), 13-17. 
intencionada, un artificio lingüístico que "da la oportunidad de hacer un trabajo que nos compensa del revuelto desorden de la realidad bruta que no se asienta". ${ }^{13}$ A partir de estos argumentos, bien podría decirse que el límite inicial que los historiadores nacionalistas impusieron a sus relatos, y a través del cual pretendieron referir el origen de los estados nacionales, amerita ser comprendido como una ficción que les posibilitó, en primer lugar, para delimitar su materia de trabajo - los hechos históricos de la nación; en segundo, para instituir un movimiento durable y discontinuo respecto a otros cursos lingüísticos o histórico-sociales - otras historias y otros modelos de organización social-; y en tercero, para dar unidad, orden, dirección y significado - formal, lógico y moral- a un número disperso y heterogéneo de hechos y circunstancias. ${ }^{14}$

Por lo que se refiere a la segunda de las marcas narrativas del discurso histórico nacionalista, el final, debe decirse que se trata del complemento estructural del comienzo, ya que cumple la función de rematar la dirección formal, lógica y moral anunciada por éste. Al modo de ver de autores como Frank Kermode y Hayden White, el final de todo relato es también una ficción que ordena, da sentido, revela la estructura inmanente a los hechos que acontecen en el medio. ${ }^{15}$ Pero ¿qué tipo de sentido es éste que entraña el cierre o final de un relato histórico? White sugiere que se trata de uno fundamentalmente moral. A su entender, un trabajo histórico alcanza plenitud narrativa cuando su final "invoca explícitamente la idea de un sistema social que sirve como un punto de referencia fijo a través del cual el flujo efímero de eventos es dotado de un sentido moral". ${ }^{16}$ Apoyado en argumentos del propio Kermode, el teórico norteamericano concibe que el historiador proyecta el significado de los hechos hacia el futuro, es decir, hacia un rasero moral más allá de su experiencia presente que le permite, más que observar, juzgar la estructura del campo histórico completo. Ese rasero moral es su ideal de sociedad. ${ }^{17}$ Con base en estos postulados, considero que el conjunto de acontecimientos que un historiador nacionalista registra en su narración es dependiente en su totalidad del final, del ideal moral y social hacia el cual los proyecta, que en su caso no es otro que la constitución del

${ }^{13}$ Edward W. Said, Beginnings. Intention \& Method (Nueva York: Columbia University Press, 1975), 50.

${ }^{14}$ Said, Beginnings..., 29-78; Lungo, L'incipit romanesque..., 34-45.

${ }^{15}$ Kermode, The Sense of an Ending..., 46; White, The Content of the Form..., 20.

${ }^{16}$ White, The Content of the Form..., 22.

${ }^{17}$ Kermode, The Sense of an Ending..., 8; White, The Content of the Form..., 22-25. 
Estado-nación y el cumplimiento de su destino histórico. Desde esta perspectiva, el lugar que cada hecho ocupa en el relato, su valor o, incluso, su estatus de realidad dependerá de su éxito o fracaso en la conducción hacia el establecimiento del orden invocado por el final de la historia nacional. ${ }^{18}$

Con plena conciencia de la necesidad de ejemplos concretos que ilustren estos apuntes teóricos sobre los comienzos y los finales de las historias nacionales, emprenderé a continuación un análisis de dichos fenómenos a partir de una serie de trabajos representativos del género historiográfico: las correspondientes historias de Portugal y de México de Alexandre Herculano y Lucas Alamán. ${ }^{19}$

La empresa ultramarina como término de la historia de Portugal

Si algo separó a Alexandre Herculano de la mayor parte de los historiadores modernos que le precedieron y que estuvieron interesados en la historia de Portugal fue que en sus narraciones historiográficas - Cartas sobre a História de Portugal (1842), História de Portugal (1846-1853), História da origem e estabelecimento da Inquisição em Portugal (1853-1859) - concibió la época de los descubrimientos y conquistas de ultramar (siglo xvi) como el término o cese de dicha historia. ${ }^{20}$ Contrario a lo que postularon, por ejemplo, el padre António Vieira - História do Futuro (1718)_, Frei Manuel dos Santos -História Sebástica (1734) - o Inácio Barbosa Machado - Fastos políticos e Militares da Antiga, e Nova Lusitánia (1745)—, quienes asumieron que, a través de la empresa ultramarina del Oriente y el Brasil, Portugal había "realizado" su telos u objetivo histórico, su "destino providencial e imperial", Herculano señaló que el también llamado "Renacimiento lusitano" no había sido sino "una época en que la tiranía, el fanatismo, la hipocresía y la corrupción" aparecían "en su natural hediondez". ${ }^{22}$ Aduciendo como prueba

${ }^{18}$ White, The Content of the Form..., 23.

${ }^{19}$ Véase arriba la nota 6.

${ }^{20}$ Para la diferenciación entre término y fin, cfr. Malcolm Bull, comp., La teoría del apocalipsis y de los fines del mundo (México: Fondo de Cultura Económica, 1998).

${ }^{21}$ Joaquim Veríssimo Serrão, A historiografia portuguesa. Doutrina e crítica, v. 3 (Lisboa: Verbo, 1972), 101, 199-202; Alexandre Herculano, História da origem e estabelecimiento da Inquisição, v. 1 (Amadora: Livraria Bertrand, 1975), 9-11; Eduardo Lourenço, Portugal como destino seguido da Mitologia da saudade (Lisboa: Gradiva, 2012), 16-19.

22 Todas las citas de la obra de Herculano son traducciones mías a la lengua castellana del texto original en portugués. 
para sostener dicha tesis la propia documentación del periodo, el autor en cuestión arguyó que la causa de aquella decadencia estaba en el régimen absolutista consolidado en Portugal durante el siglo Xvi. "Bajo el imperio de una sola voluntad" - decía refiriéndose, principalmente, al reinado del monarca absoluto D. João III (1521-1557), “El Piadoso”, fundador de la Inquisición portuguesa-quedaron políticamente anulados los elementos sociales aristocrático y democrático - la nobleza y la burguesía - ${ }^{23}$ y con ellos, también la unidad orgánica de la nación. De ahí, agregó, sólo fue un paso para que, en 1580, el "Diablo de Mediodía”, Felipe II, acabase con la independencia de Portugal y reinase él solo "en todas las Españas". ${ }^{24}$

La oposición que Herculano hizo a la comprensión del siglo XVI como telos de la historia nacional portuguesa revela plenamente su sentido al observarla a la luz de la inconformidad que también demostró respecto a la situación político-social de su propio tiempo. Me refiero, específicamente, a su aversión por el sistema político-administrativo centralista vigente en Portugal desde el comienzo de la Revolución liberal (1832) contra el rey absolutista D. Miguel: ${ }^{25}$

La centralización, en la copia portuguesa, como hoy existe y como la sufrimos, es el fideicomiso legado por el absolutismo a los gobiernos representativos, pero enriquecido, exagerado; es, disculpadme la frase, el absolutismo liberal. La diferencia está en esto: anteriormente los frutos que daba el predominio de la centralización se suponía eran recogidos por un hombre llamado rey: hoy cógenlos seis o siete hombres llamados ministros [...] dicen después que todo es del país, por el país y para el país. Y no mienten. El país del que hablan es el país nominal; es su clientela, su funcionalismo; es el propio gobierno; es la traducción moderna de la frase de Luis XIV: "El Estado soy yo", salvo la sinceridad. ${ }^{26}$

${ }^{23}$ Herculano, História da origem e estabelecimiento da Inquisição..., v. 3, 43.

${ }^{24}$ Alexandre Herculano, "Cartas sobre a História de Portugal”, en Opúsculos, v. 5 (Lisboa: Viuva Bertrand \& Ca., 1886), 136-137, 140-149.

${ }^{25}$ El centralismo político-administrativo portugués tomó inspiración de las legislaciones jacobina -leyes del 14 y 22 de diciembre de 1789- y napoleónica —ley del 28 de Pluviôse, año VIII-, y fue sancionado tanto por la legislación cartista de 1832 -decreto n. 23 de José Xavier Mouzinho da Silveira-, como por el Código Administrativo de 1842. Fernando Catroga, A geografia dos afectos pátrios. As reformas político-administrativas (séc. XIX-XX) (Coimbra: Edições Almedina, 2014), 29, 49, 54-55.

${ }^{26}$ Alexandre Herculano, "Carta aos Eleitores de Sintra” [1858], en Opúsculos, v. 2 (Lisboa: Viuva Bertrand \& Ca., 1873), 237-238. 
Como otrora lo detectara Alexis de Tocqueville en De la démocratie en Amerique (1835-1840) y en L'Ancien Régime et la Révolution (1856), Herculano observó una solución de continuidad entre el absolutismo de los siglos XVI-XVIII y el centralismo liberal decimonónico. ${ }^{27}$ "La centralización de la soberanía; la centralización de la administración por el ejecutivo; la centralización de la justicia; la centralización de la fuerza pública", en otras palabras, la concentración absoluta del poder político y de la administración en las manos de un gobierno central - ya no en las de un rey- no era para él otra cosa que simple y llano "despotismo" disfrazado de "gobierno representativo". 28 "Este bello invento" del centralismo, afirmaba, "había heredado del absolutismo todos los harapos de la púrpura que las ideas y las revoluciones habían desgarrado, y remendó con ellos un traje nuevo". ${ }^{29}$ Así, en vista de esta concepción de la identidad entre el absolutismo de los siglos anteriores y el centralismo de su propio tiempo, no extraña el encono del autor contra la época de los descubrimientos y las conquistas de ultramar, de la cual "todavía hoy el [nuevo] absolutismo, ignorante de su propio pasado, osa gloriarse": 30 se trataba del símbolo histórico de aquella forma de Estado que, lo mismo en su versión de monarquía absoluta que en la de monarquía constitucional centralista, hacía cuatro siglos que subyugaba al organismo-nación portugués bajo su estructura "artificial” de "pirámide jerárquica”, con su "juego [burocrático] de funciones regulares" y "racionales". ${ }^{31}$

Para Herculano, el desmantelamiento del sistema político-administrativo centralista, de ese nuevo-viejo orden social “despótico" al que, en una servil imitación del sistema francés, habían derivado los regímenes supuestamente liberales de la posrevolución portuguesa (1820-1851) pasaba tanto por la destrucción del mito de la "Edad de oro imperial" como por el reconocimiento del verdadero origen de la nación. Contrario a lo que argumentaba el publicista, contemporáneo suyo y partidario del liberalismo centralista, António Lopes de Mendoça, esto es, que Portugal había nacido entre los siglos XV y XVI "bajo la idea de la centralización, bajo la unidad

${ }^{27}$ Pierre Rosanvallon, El momento Guizot. El liberalismo doctrinario entre la Restauración y la Revolución de 1848 (Buenos Aires: Biblos, 2015), 48-49; Catroga, A geografia dos afectos pátrios..., 49-50.

${ }^{28}$ Alexandre Herculano, “Os Vínculos” [1856], en Opúsculos, v. 4 (Lisboa: Viuva Bertrand \& Ca., 1879), 35-36.

${ }^{29}$ Citado en José Saravia, Herculano desconhecido (Povoa de Varzim: Publicações Europa-América, 1971), 205-206.

${ }^{30}$ Herculano, História da origem e estabelecimento da Inquisição..., v. 3, 43.

${ }^{31}$ Herculano, História da origem e estabelecimento da Inquisição..., v. 3, 205-209. 
monárquica" y contra "los egoísmos locales", ${ }^{32}$ el autor de la História de Portugal defendió que su patria se había constituido como "nacionalidad" en el siglo XII, en la "época municipal", y que, por lo tanto, en concordancia con ese "origen", su "destino" no era convertirse en "imperio", sino ser una nación "libre", "burguesa”, "municipal". 33

Esta tesis burguesa y municipalista del origen y destino de Portugal, Herculano la fundaba en el examen crítico de los forais o cartas de constitución municipal medievales. En esos documentos - sostenía- era reconocible que, en su origen, la monarquía portuguesa había surgido al amparo de la institución municipal, la cual, a pesar de su "imperfección", ya desde entonces había revelado su carácter como "baluarte de la libertad" de las clases burguesas frente a la opresión de las clases poderosas - el clero y la aristocracia: ${ }^{34}$

¿Por qué se restauraba hasta cierto punto la organización de las provincias romanas, esencialmente municipal? Lo que se casaba más naturalmente con el espíritu de la época era el método contrario: las influencias del feudalismo eran enérgicas entre nosotros en la cuna de la monarquía; los delegados del poder real y los poseedores de tierras de la corona procuraban dar a sus cargos y préstamos, que no pasaban, aquéllos de delegaciones, éstos de verdaderos beneficios, el carácter de feudos. Y sin embargo, el progreso del sistema opuesto fue rápido y sorprendente: al final del reinado de D. Afonso III, Portugal estaba cubierto de concejos. Al paso que en los países esencialmente feudales estas pequeñas repúblicas casi siempre se formaban por la revuelta y en medio de grandes luchas, entre nosotros aconteció lo que M. Thierry niega y muestra ser una opinión falsa relativamente a Francia: esto es, fueron principalmente instituidas por voluntad del rey, aunque no falten fundamentos para creer que algunas de las más antiguas cartas de comuna o forales, entre éstas la de Coimbra en tiempo de D. Henrique, se obtuvieron por violencia, y después de una lucha en que la autoridad soberana no llevó la mejor parte. ${ }^{35}$

La característica emblemática del municipio original portugués, aquella que, según apuntaba el autor de este extracto, lo diferenciaba del caso francés - e incluso del leonés-castellano- era que aquél no había surgido a par-

${ }^{32}$ Catroga, A geografia dos afectos pátrios..., 314.

${ }^{33}$ Saraiva, Herculano desconhecido..., 217.

${ }^{34}$ Alexandre Herculano, História de Portugal. Desde o começo da Monarquia até ao fim do Reinado de Afonso III, v. 2 (Lisboa: Bertrand Editora, 2007), 190-191.

35 Alexandre Herculano, "Apontamentos para a história dos bens da Coroa e dos foraes" [1843-1844], en Opúsculos, v. 6 (Lisboa: Viuva Bertrand \& Ca., 1884), 219-220. 
tir de ninguna revolución contra el monarca, sino de su institución por parte de este último. En contraste con la interpretación de historiadores de allende los Pirineos como Augustin Thierry, para quien las cartas comunales eran testimonios de la liberación burguesa ganada por fuerza al rey y a la nobleza francesas, ${ }^{36}$ Herculano comprendió los forais, las cartas de comuna otorgadas por los primeros reyes portugueses, como pruebas del pacto primitivo entre el monarca y sus súbditos "ingenuos" - hombres libres-. Se trataba de una alianza pragmática: la monarquía necesitaba los recursos económicos - dinero, especie, trabajo- que las villas aportaban, así como una base de apoyo militar para emprender la conquista del Algarve o someter a los nobles rebeldes; mientras que los burgueses precisaban de protección contra sus explotadores - la nobleza y el alto clero-. Con todo, esa alianza interesada daba cuenta de la capacidad política del pueblo: los forais eran la prueba material del reconocimiento legal de la asociación burguesa como "concejo municipal" - como "entidad política" compuesta por "hombres libres". ${ }^{37}$

Ahora bien, más allá de calificar al municipio medieval como una barrera de la burguesía contra los abusos del clero y la nobleza, la razón principal por la cual Herculano puso tanto énfasis en designar a dicha institución como la célula original del Estado-nación portugués estriba en que la consideró como la encarnación de la "única libertad verdadera". ${ }^{38}$ Con Benjamin Constant, Alexis de Tocqueville y el propio Augustin Thierry, ${ }^{39}$ el historiador luso tuvo al municipio medieval como la "institución de libertad" por excelencia, por cuanto se trataba de la primera instancia de la vida social que aseguraba legalmente "el libre movimiento del individuo dentro de la esfera de su propia acción" - la "igualdad civil" - . ${ }^{40}$ Esa legalidad quedaba establecida por los forais o cartas de constitución municipal, las cuales, allende de ser "cartas de población", eran, por un lado, "códigos que instituían o fijaban el derecho público local y que constituían por agregación de varios individuos una persona moral, una entidad social con cierta autonomía, la

${ }^{36}$ Agustine Thierry, Lettres sur l'histoire de France (París: Just Tessier Librarie-Editeur, 1842), 210-271; Rosanvallon, El momento Guizot..., 158.

${ }^{37}$ Herculano, "Apontamentos para a História...", 226-237.

${ }^{38}$ Herculano, História de Portugal..., v. 2, 36-37.

${ }^{39}$ Benjamin Constant, Écrits politiques (París: Gallimard, 1997), 423-433; Alexis de Tocqueville, De la démocratie en Amerique, v. 1 (París: Éditions Gallimard, 1986), 111-124; Thierry, Lettres sur l'histoire..., 210-466; Rosanvallon, El momento Guizot..., 45-52.

${ }^{40}$ Herculano, "Os Vínculos...", 53; Herculano, História de Portugal..., v. 2, 325; Catroga, A geografia dos afectos pátrios..., 37-40. 
civitas de la jurisprudencia romana, más o menos profundamente caracterizada"; y por el otro, diplomas de "derecho público [general]" que establecían "los deberes y los derechos de los gremios y de los individuos que los componían en relación con el Estado [la sociedad en general]". ${ }^{41}$

Valorada la importancia que Herculano atribuyó al municipio medieval portugués, conviene finalmente subrayar que, no obstante las virtudes que reconoció en esta institución, nada fue más lejano a su pensamiento que imaginar que se trataba de una entidad política perfecta que era viable restaurar como tal en el presente. Por el contrario, lo que deseaba era más bien que se conservaran las obras "útiles del tiempo pasado", mejorando todo lo que de este último no sirviera. La suya era la actitud del conservador o bien la del reformista, que no la del reaccionario. "Amo - apuntaba en un opúsculo de 1856 - el pasado de mi país, y sus tradiciones primitivas [...] pero de eso no se sigue que desconozca la experiencia de los siglos, las ventajas de la civilización y las verdades adquiridas por las ciencias sociales." Su intención de "restaurar" las "fórmulas sociales" medievales -el municipio-, su deseo de "vincular la libertad moderna a la libertad antigua [medieval]" no significó, pues, para él un querer volver a aquella época plagada de "cosas incompletas, bárbaras". ${ }^{42}$ Tal pretensión era, a su entender, completamente absurda. En cambio, lo que buscaba era "conservar" las instituciones valiosas creadas por los portugueses del Medioevo, mejorarlas y desechar las que fueran "ruines". Esto en términos concretos quería decir que anhelaba "restaurar, en armonía con la ilustración del siglo, las instituciones municipales, perfeccionarlas sí, pero acordes con su índole, en sus elementos, con las de la Edad Media". ${ }^{43}$

El remedio que, a consideración de Herculano, colmaría las deficiencias de la vida municipal medieval consistía básicamente en tres modificaciones al sistema: primero, el nombramiento de jueces territoriales, no electos por los burgueses; segundo, la configuración de una separación moral - verdadera separación democrática- entre las asociaciones burguesas y las clases privilegiadas; y tercero, la homogeneización de las garantías políticas, judiciales y tributarias de todos los municipios portugueses. ${ }^{44}$ Ahora bien, esta triple propuesta de solución podía, en realidad —y así lo hizo el historiador-

${ }^{41}$ Herculano, História de Portugal..., v. 2, 355, 601.

42 Alexandre Herculano, "Mousinho da Silveira" [1856], en Opúsculo, v. 2 (Lisboa: Viuva Bertrand \& Ca., 1873), 216.

${ }^{43}$ Herculano, História de Portugal..., v. 2, 189-190.

${ }^{44}$ Herculano, História de Portugal..., v. 2, 631-633. 
sintetizarse en una sola: en tanto que el problema de fondo del municipalismo medieval portugués radicaba en que cada municipio velaba únicamente por sus propios intereses y no por los de la sociedad en general, había que lograr que los diversos elementos municipales que componían la nacionalidad portuguesa dejasen de existir "entre sí" y juntos constituyeran un "en sí". ${ }^{45}$ A esta tarea, lo reconoció el mismo Herculano, había contribuido el propio absolutismo. La gran labor histórica de ese régimen político, aquélla por la cual se justificaba su existencia histórica - que no su calidad de telos de la historia portuguesa - radicaba en que había acabado con "la lucha continua en que vivían las diversas clases para defender o dar predominio a sus propios intereses", logrando así "una cierta homogeneización de las costumbres para los pueblos de una misma nación". ${ }^{46}$ Sin embargo, su defecto, la razón que llevó a la pérdida de la independencia de Portugal en el siglo XVI, radicaba en que, en el curso de su labor, había oprimido a la libertad municipal. Era necesario, entonces, culminar, perfeccionar, tanto la obra del municipalismo medieval como la del absolutismo moderno, y para lograrlo había que crear un régimen que garantizara la libertad municipal sin la "anarquía", y que protegiera el orden sin la "tiranía" del rey o de la nobleza sobre la libertad. ${ }^{47}$ En pocas palabras, había que hacer surgir un régimen que configurara Portugal como una auténtica "nación": como una "organización" de los distintos "patriotismos locales" — una federación de municipios. ${ }^{48}$

La conquista como comienzo prestigioso de la historia de México

Doblemente violento fue el comienzo ideado por Lucas Alamán para su historia de México. En primer lugar, porque fijó como punto de partida de su relato un hecho "de la violencia y de la fuerza": la Conquista de MéxicoTenochtitlán y el establecimiento del gobierno español en la América

${ }^{45}$ Herculano, "Cartas sobre a história de Portugal...", 150.

${ }^{46}$ Herculano, "Cartas sobre a história de Portugal...", 150; Saraiva, Herculano desconhecido..., 230-231. Aunque Herculano consideró a la época del absolutismo (siglos XVI-VIII) como un periodo en que Portugal había "traicionado" su destino, pensó asimismo que había sido un trance necesario para la consecución de la meta municipalista, pues "era preciso que las naciones se habilitasen, en la tiranía de la opresión, para la libertad". Herculano, "Cartas sobre a história de Portugal...", 150.

${ }^{47}$ Herculano, História de Portugal..., v. 2, 115-116; Herculano, "Cartas sobre a história de Portugal...”, 150.

${ }^{48}$ Saraiva, Herculano desconhecido..., 191-194. 
septentrional; ${ }^{49}$ en segundo, porque para dar autoridad a su tesis emprendió un virulento ataque hacia otros discursos o interpretaciones sobre el origen de la nación mexicana. Los objetos particulares de su embiste fueron básicamente dos textos: la Historia de la Revolución de la Nueva España, antiguamente Anáhuac (1813) de Fray Servando Teresa de Mier y el Cuadro histórico de la Revolución de la América mexicana (1823-1846) de Carlos María de Bustamante. Como ha sido señalado por diversos críticos -Elías Palti y Joshua Simon, entre ellos-, la discrepancia de Alamán en relación con los mencionados trabajos tuvo que ver con la premisa sobre la cual el padre Mier y Bustamante construyeron sus interpretaciones del proceso de independencia mexicano: me refiero al argumento de que el movimiento del cura Hidalgo, pero sobre todo la demanda de independencia de José María Morelos, eran legítimos en tanto que la finalidad de los mismos había consistido en recuperar los derechos, la soberanía de una nación mexicana preexistente a la Conquista española. ${ }^{50}$ Para el historiador guanajuatense, dicho aserto era un desvarío, pues

No eran los restos de las naciones que antes dominaron el país las que promovían la independencia, ni ésta tenía por objeto reponerlas en sus derechos usurpados por la conquista; promovían los descendientes de los conquistadores, que no tenían otros derechos que los que les había dado esa misma conquista, contra lo cual han declamado [ciertos escritores nacionales] con una especie de frenesí imposible de explicar, como si fuesen los herederos de los pueblos conquistados y estuviesen en obligación de vengar sus agravios. ${ }^{51}$

Contra el argumento de algunos criollos o "descendientes de los conquistadores" de asumirse como "herederos" o representantes de la causa de los indígenas conquistados, Alamán sostenía que ninguna nación mexicana

${ }^{49}$ Lucas Alamán, Disertaciones sobre la historia de la República Mejicana: desde la época de la conquista que los españoles hicieron, a fines del siglo XV y principios del XVI, de las islas $y$ continente americano, hasta la independencia, v. 1 (México: Imprenta de D. José Mariano Lara, 1844-1849), 136-139.

${ }^{50}$ Simon, The Ideology of Creole Revolution..., 140-142; Elias Palti, "Lucas Alamán y la involución política del pueblo mexicano. ¿Las ideas conservadoras “fuera de lugar'?”, en Conservadurismo y derechas en la historia de México, v. 1, coord. de Erika Pani (México: Fondo de Cultura Económica/Consejo Nacional para la Cultura y las Artes, 2009), 309-310; William Fowler y Humberto Morales Moreno, coords., El conservadurismo mexicano en el siglo XIX (1810-1910) (Puebla: Benemérita Universidad Autónoma de Puebla, 1999), 63.

${ }^{51}$ Lucas Alamán, Historia de México. Desde los primeros movimientos que prepararon su independencia en el año de 1808 hasta la época presente, v. 1 (México: Jus, 1942), 126. 
había existido antes de la llegada de los españoles al territorio de lo que posteriormente sería la Nueva España. Por el contrario - afirmaba- hacia comienzos del siglo XVI la América del Norte estaba poblada por múltiples tribus y naciones, a veces independientes, en otras sujetas a caciques y principados mayores. Incluso la situación de la "monarquía mexicana”, el Estado más grande y poderoso de la región, era bastante "irregular", pues se hallaba afectada y debilitada por los problemas propios de un "sistema feudal" en el cual la "división en muchas secciones pequeñas, vecinos descontentos o declaradamente enemigos, súbditos poderosos propensos a la desobediencia” hacían imposible la consolidación de una auténtica unidad nacional. A su modo de ver, esta última sólo había sido posible luego de la toma de México-Tenochtitlán por los conquistadores españoles, cuando gracias al gobierno que establecieron "se formó una sola nación de todas estas partes separadas [México, el Reino de Michoacán y el de Tehuantepec], y este elemento precioso de la unidad nacional vino a ser el fundamento de la grandeza a que la república podrá llegar algún día si sabe conservarla". ${ }^{2}$

A la luz de estas afirmaciones, no parecerá aventurado sugerir que la polémica tesis alamaniana de que el origen de la nación mexicana estaba en la Conquista - la cual desarrolló en sus dos obras históricas mayores, las Disertaciones sobre la historia de la República Mexicana (1844-1849) y la Historia de México (1849-1852) - no es otra cosa sino una toma de posición política. ${ }^{53}$ La disputa historiográfica sobre el origen de México que, entre las décadas de 1830 y 1850, enfrentó intelectualmente, entre otros, a Carlos María de Bustamante, Lucas Alamán y Lorenzo de Zavala —este último, por ejemplo, a diferencia de los dos primeros, haciendo tabula rasa de los pasados prehispánico y colonial, propuso en su Ensayo histórico de las revoluciones de México (1831) que "la historia interesante de México no comienza verdaderamente sino en aquel año memorable [1808]" — ${ }^{54}$ amerita ser vista como una suerte de sublimación o simbolización de otra controversia que por entonces desgarraba a la sociedad de la joven República mexicana, o por lo menos a sus élites políticas urbanas y provincianas: hablo de la contienda sobre el tipo constitución política -republicana o monárquica,

${ }^{52}$ Alamán, Disertaciones sobre la historia..., v. 1, 14-17, 161-162.

${ }^{53}$ Alamán, Disertaciones sobre la historia..., v. 1, 1; Alamán, Historia de México..., v. 1, 3; Charles Hale, El liberalismo mexicano en la época de Mora (1821-1853) (México: Siglo XXI, 1972), 20-21.

${ }^{54}$ Lorenzo de Zavala, Obras. Ensayo crítico [sic] de las revoluciones de México desde 1808 hasta 1830 (México: Porrúa, 1969), 11. 
federalista o centralista, liberal o conservadora- que debía asumir el Estado mexicano. ${ }^{55}$

Para detectar cuál fue la propuesta de constitución política de México que Alamán simbolizó en su relato de la Conquista, hace falta, en primer lugar, dar cuenta de los componentes y características del relato en cuestión. Con alguna frecuencia se ha afirmado que en la construcción de dicho relato el historiador guanajuatense siguió muy de cerca, si no es que parafraseó, a la History of the Conquest of México (1843) del estadounidense William Prescott. ${ }^{56} \mathrm{~A}$ mi modo de ver esta interpretación se sostendría siempre y cuando se consideraran, exclusivamente, los hechos guerreros de la narración, quiero decir, aquellos hechos "violentos y brutales" encarnados por la "heroica" gesta de los españoles y la "trágica" caída de los mexicas. ${ }^{57}$ No obstante, lo cierto es que la Conquista de Alamán de ninguna manera podría reducirse a los mencionados episodios. La parte más original de su relato, la que concentra su atención de forma mucho más profunda y significativa, es aquella que da cuenta de los acontecimientos relacionados con la fundación de instituciones políticas a instancias de los españoles. No extraña, por lo mismo, el lugar privilegiado que en esa historia ocupa el conocido episodio de la constitución del ayuntamiento de la Villa Rica de la Vera Cruz el 10 de julio de 1519 bajo la iniciativa de Hernán Cortés. ${ }^{58}$

Ahora bien, valorar la relevancia atribuida por Alamán al acontecimiento de la fundación del primer ayuntamiento de la América continental implica reparar en la relación de parentesco que estableció entre los municipios originales novohispanos - la Villa Rica, Segura de la Frontera, la ciudad de México y Medellín-y los municipios ibéricos del siglo xv. ${ }^{59}$ Tal filiación revela su envergadura cuando se repara en la caracterización que el historiador guanajuatense hizo de los últimos no sólo como las instituciones más "liberales" de su época — garantes de la "libertad" de los "vecinos" de las comunidades ibéricas para participar en la cosa pública y

${ }^{55}$ Cfr. Michael P. Costeloe, La república central en México, 1835-1846. "Hombres de bien" en la época de Santa Anna (México: Fondo de Cultura Económica, 2000); Jesús Reyes Heroles, El liberalismo mexicano, 3 v. (México: Fondo de Cultura Económica, 1974); Hale, El liberalismo mexicano...

${ }^{56}$ Enrique Plasencia de la Parra, "Lucas Alamán”, en Historiografía mexicana, v. 3, El surgimiento de la historiografía nacional, coord. de Virginia Guedea (México: Universidad Nacional Autónoma de México, 1997), 311.

${ }^{57}$ Alamán, Disertaciones sobre la historia..., v. 1, 131-137, 151.

58 Alamán, Disertaciones sobre la historia..., v. 1, 61-62.

${ }^{59}$ Alamán, Disertaciones sobre la historia..., v. 1, 167-168. 
velar, a través de la "representación" en Juntas, por el "interés general"-, sino también como aquellas entidades políticas que, junto a la monarquía castellana, posibilitaron la fundación de la "nación española" en vísperas del Descubrimiento de América. Al frente del "elemento popular", sostuvo, los reyes castellanos unieron "a sus coronas los grandes feudos desmembrados de ellas", formando "cuerpos de nación de los que hasta entonces no habían sido más que miembros débilmente ligados entre sí y prontos a sublevarse contra el soberano". Con base en esta premisa, en tanto que vástagos del tronco castellano, Alamán reconoció en los municipios novohispanos la semilla de la libertad política y los cimientos de la unidad y la nacionalidad mexicanas. Esta tesis se deja ver con toda claridad cuando afirma que aquellas "instituciones liberales de que España gozaba, más que ninguna otra nación en aquel siglo [xv]", y que "habían venido a ser un hábito para todos los españoles [...] México las tenía [por igual]”; agrega que si no hubiera sido porque en la propia España las "instituciones liberales" fenecieron en los "campos de Villanar", pisoteadas por el "poder absoluto de Carlos V", "acostumbrada la nación [mexicana] a discutir libremente sus propios intereses, la independencia se habría hecho por sí misma" casi de forma inmediata a la Conquista. ${ }^{60}$

La preponderancia narrativa que Alamán concedió a la cuestión municipal en la empresa de la Conquista da cuenta, hasta donde lo alcanzo a observar, de sus ideales de reorganización político-administrativa del Estado mexicano. A este respecto vale la pena no olvidar que, hacia finales de la década de 1840, como presidente del Ayuntamiento de la ciudad de México (julio-diciembre de 1849), el experimentado político intentó, de hecho, construir la plataforma que le permitiera proyectar sus intereses -que eran los de la mayor parte de la élite criolla capitalina- en el ámbito nacional. ${ }^{61}$ Con la finalidad de esclarecer cuál fue la relación concreta que el historiador guanajuatense concibió entre el municipio original novohispano y su plan de reorganización político-administrativa será vital estimar las afirmaciones contenidas en aquel texto que la crítica ha caracterizado

${ }^{60}$ Alamán, Disertaciones sobre la historia..., v. 1, 7-10, 167-168; Alamán, Historia de México..., v. 1, 34.

${ }^{61}$ Alfonso Noriega, El pensamiento conservador y el conservadurismo mexicano, v. 1 (México: Universidad Nacional Autónoma de México, Instituto de Investigaciones Jurídicas, 1972), 90; Simon, The Ideology of Creole Revolution..., 149. 
como su "Testamento político", es decir, el capítulo XI de la "Parte segunda" de la Historia de México: ${ }^{62}$

De estas inclinaciones que han echado raíces en el espíritu público, una de las más preponderantes y que ha contribuido mucho al origen, restablecimiento y conservación del sistema federal, es la adhesión a las localidades, o lo que se llama provincialismo, la cual reducida a justos y prudentes límites debe producir el buen resultado, de que se administren con más cuidado los intereses particulares de cada población y de cada Estado, y es a la que se debe que se haya fomentado en ellos la instrucción y que se hayan hecho algunas obras útiles de comodidad y ornato y aun de mera ostentación. Esta afición al lugar en que cada uno nació, está radicado o tiene sus propiedades, se echa de ver en algunos conatos de revolución en que también se distingue el respeto y adhesión a la antigua capital de la nación: así vemos separarse a Colima de Guadalajara en 1823, para depender del gobierno de México como territorio de la federación; esto mismo han solicitado Orizaba, Mazatlán, Aguascalientes y otras poblaciones, y es a lo que propenden muchas otras, resultando de aquí que si se dividiesen ahora los actuales Estados en tantos cuantos son los departamentos o distritos que los componen, se haría una cosa muy bien recibida por todos estos departamentos, y que por sí sola con las extensas consecuencias que tendría, bastaría para salir de todas las dificultades en que la nación se halla, estableciéndose en ella un orden sencillo, simétrico, uniforme y poco costoso en todas sus partes. Antes de explicar estos puntos, debo decir que ésta no es una novedad, sino el restablecimiento del antiguo sistema de gobierno de la Nueva España, antes que se creasen las intendencias que después vinieron a ser estados, y que el principio es de tal manera general, que no deba sufrir excepciones con respecto a aquellos estados de corta superficie y población, como Chiapas, Nuevo León, Querétaro y Tabasco, que no admiten mayor división, pero que con el hecho de ejecutarla en los de más extensión y número de habitantes, tomando cuando el caso lo pida, alguna parte de los unos para agregarla a otros, vendrían a quedar todos con la igualdad necesaria, como se practicó en Francia, cuando se hizo la división de los antiguos estados y provincias en departamentos: división que tan benéfica ha sido a aquel país, que han conservado todos los gobiernos que se han sucedido desde la Asamblea Nacional, y que está hoy ligada con todo el sistema administrativo de aquella nación. ${ }^{63}$

Como ha sido señalado por distintos especialistas - entre ellos Alfonso Noriega y Enrique Plasencia-, el largo párrafo aquí recuperado da cuenta

62 Plasencia de la Parra, “Lucas Alamán...”, 326.

${ }^{63}$ Alamán, Historia de México..., v. 5, 582-583. 
de una parte del plan político-administrativo concreto que, hacia 1852, Lucas Alamán buscó implementar para rescatar al país del caos en que lo tenía sumido una élite política que no había logrado recuperarse de la derrota militar sufrida frente a los Estados Unidos de América en la guerra de 1846$1848 .{ }^{64}$ Dicho plan, a mi modo de ver, tuvo por epicentro al municipalismo, considerado por el historiador como una herencia de la Conquista. ${ }^{65} \mathrm{~A}$ primera vista, esta afirmación podría parecer aventurada o incluso equivocada, teniendo en mente, en primer lugar, el pasado centralista del autor -expuesto de forma sintética en su Examen imparcial de la administración del general vicepresidente don Anastasio Bustamante (1835)— ${ }^{66} \mathrm{y}$, en segundo, recordando la famosa "Carta a Santa Anna" que escribió un año después de terminada su Historia de México (el 23 de marzo de 1853), y donde se declaró "contra la federación: contra el sistema representativo por el orden de elecciones que se ha seguido hasta ahora; contra los ayuntamientos electivos y contra todo lo que se llama elección popular, mientras no descanse sobre otras bases" ${ }^{67}$ Estas palabras fácilmente podrían aducirse como prueba para destruir la viabilidad de la hipótesis de un Alamán municipalista, ya no se diga de uno federalista. Con todo, juzgo que sería prudente poner más atención en ese pequeño matiz consignado al final de su diatriba: "mientras no descanse sobre otras bases". Y es que varias afirmaciones de su misma Historia de México demuestran que Alamán era, de hecho, bastante afecto a un cierto tipo de sistema representativo y a una suerte de "federalismo restringido" ${ }^{68}$ La prueba más fehaciente de ello se encuentra en las páginas iniciales del primer volumen de dicho texto, en las cuales ensalza la forma de organización política municipalista, representativa y semifederativa adoptada por los fundadores de la Nueva España. ${ }^{69}$

Evidentemente, el régimen que Alamán deseaba ver constituido en México no era un sistema representativo y federal como el que habían avalado los liberales radicales como el padre Mier y Zavala, fundado en la tesis

${ }^{64}$ Noriega, El pensamiento conservador..., v. 1, 89; Plasencia de la Parra, "Lucas Alamán...”, 326.

${ }^{65}$ Alamán, Historia de México..., v. 1, 6.

${ }^{66}$ Lucas Alamán, Examen imparcial de la administración de Bustamante (México: Consejo Nacional para la Cultura y las Artes, 2008), 195-221.

${ }^{67}$ Gastón García Cantú, comp., El pensamiento de la reacción mexicana: historia documental, 1810-1962 (México: Empresas Editoriales, 1965), 342-344.

${ }^{68}$ Noriega, El pensamiento conservador..., v. 1, 89.

${ }^{69}$ Alamán, Historia de México..., v. 1, 34. 
roussoniana de la soberanía popular ${ }^{70}$ y en la idea de la independencia plena de las localidades - de los municipios y los estados- respecto al centro ejecutivo del poder. ${ }^{71}$ Si se observan de manera conjunta las imágenes de la organización político-administrativa que el historiador guanajuatense concibió existente durante los primeros años de la Colonia y aquella que propuso para la sociedad mexicana de su presente, del análisis de las dos se podrá deducir que su ideal consistía, en primer lugar, en una división "simétrica, uniforme" del país en pequeños departamentos, esto para evitar las disputas internas en estados que incluyeran municipalidades de distinto clima y poder económico; y en segundo, que todas esas partes constitutivas del país, aunque independientes en sus asuntos locales -independencia municipal en sus "negocios administrativos y judiciales", en la elección de sus autoridades e incluso en la elección de sus representantes a las juntas locales y a la Junta Nacional o Congreso- fueran dependientes y equidistantes, en lo económico, del Congreso nacional formado por un diputado de cada departamento, cuya función principal sería formular un plan de egresos e ingresos al cual tendrían que ajustarse las localidades; y en lo político, de un Ejecutivo fuerte y responsable - preferentemente un monarca y su consejo-, esto es, provisto de todas las capacidades legales para hacer sentir su autoridad en, y responder frente a, la nación entera. ${ }^{72}$ De todo lo anterior es posible deducir que Alamán no abominaba en realidad de "los principios de la federación”. De hecho, del análisis de sus dos trabajos históricos mayores se infiere que, en tanto que el sistema federal estaba ya enraizado en "el espíritu público”, lo que quería más bien —en una maniobra de cariz eminentemente burkeano- ${ }^{73}$ era su conservación sublato jure nocendi, es decir, acotándolo a sus "justos y prudentes límites", "quitándole el derecho de hacer daño", para "que se multiplicaran todos los medios de hacer el bien, generalizándose cuanto puede tener de útil ese sistema". ${ }^{74}$

Finalmente, considero relevante subrayar que la solución municipalista-centralista sustentada por Alamán - quien, es bien sabido, era cercano

${ }^{70}$ Servando Teresa de Mier, Obras Completas, v. 4, La formación de un republicano (México: Universidad Nacional Autónoma de México, 1988), 196.

${ }^{71}$ Hale, El liberalismo mexicano..., 62.

72 Alamán, Historia de México..., v. 5, 583-589; García Cantú, comp., El pensamiento de la reacción mexicana..., 251-257; Simon, The Ideology of Creole Revolution..., 150-151.

${ }^{73}$ Edmund Burke, Reflections on the Revolution in France and other Writings (Nueva York: Everyman's Library, 2015), 452-456.

${ }^{74}$ Alamán, Historia de México..., v. 5, 590; Noriega, El pensamiento conservador..., v. 1, 87-88; Simon, The Ideology of Creole Revolution..., 149. 
al pensamiento político conservador $-{ }^{75}$ no era ajena al juicio de contemporáneos suyos ubicados del lado opuesto del espectro ideológico. ${ }^{76} \mathrm{Un}$ ejemplo claro de esto es el caso de José María Luis Mora. Como lo ha descrito Charles Hale en su clásico estudio sobre el liberalismo mexicano de la primera mitad del siglo XIX, aunque es cierto que Mora tuvo a la "iniciativa local" como el "fundamento verdadero del sistema federal y como un aspecto de su proyecto de la limitación de la autoridad absoluta para preservar la libertad individual", al igual que su paisano y colega Lucas Alamán, estimó necesaria la existencia de "un control administrativo centralizado", $\mathrm{y}$ de forma concreta de un "sistema de prefectos [nombrados por el gobierno federal] con ayuntamientos administrativos" para evitar los males de "la ignorancia local y del reinado de los caciquillos". A reserva de un estudio de mayor calado que profundice en la comparación de los modelos político-administrativos defendidos por estas dos figuras -las más lúcidas, tal vez- de la escena política e historiográfica mexicana de la primera mitad del siglo XIX, bien podría sugerirse, también con Charles Hale, que en ambos casos estaríamos frente a la aparente "anomalía" de un ideal de "constitución estatal centralista dentro de un sistema federalista". ${ }^{77}$

Conclusiones: la historiografía nacional como mito

La escritura de la historia desempeñó un papel de suma relevancia en los procesos de construcción y consolidación de los Estados nacionales que tuvieron lugar en Europa y América durante el siglo xıx. Los casos estudiados en el presente artículo, las historias nacionales de Alexandre Herculano y Lucas Alamán, dan cuenta de la labor de acompañamiento, postulación y legitimación de modelos de Estado-nación desarrollada por ese tipo de discursos. Como lo demuestran los análisis aquí emprendidos, ni el historiador portugués ni el mexicano propusieron en sus trabajos Estados nacionales ideológicamente neutros. Por el contrario, cada cual en su respectivo

${ }^{75}$ Noriega, El pensamiento conservador..., v. 1, 87-88; Simon, The Ideology of Creole Revolution..., 149 .

${ }^{76}$ Raymond Buve, "Los municipios y el difícil proceso de formación de la nación en el siglo XIx. Algunas reflexiones sobre Tlaxcala”, en Nación y municipio en México, siglos XIX y xx, coord. de Sergio Miranda Pacheco (México: Universidad Nacional Autónoma de México, Instituto de Investigaciones Históricas, 2012), 19-21.

77 Hale, El liberalismo mexicano..., 94-95. 
horizonte de enunciación pugnó por el establecimiento de un tipo específico de constitución política de Estado-nación. Cabe subrayar, no obstante, que ninguno enfrentó el desafío de manera burda, esto es, escribiendo meros panfletos de apariencia histórica - lo que Benedetto Croce llamaría "historia retórica"-, sino configurando narraciones de la historia nacional que, cimentadas en un depurado aparato crítico, expresaron de forma simbólica los ideales políticos sobre lo que debía ser la constitución nacional.

Con la finalidad de comprender el tipo de discurso creado por historiadores como Herculano y Alamán, pareciera factible recuperar la caracterización hecha por Benedict Anderson del discurso nacionalista como una "imagen de comunión", esto es, como un discurso abocado a la "fabricación" de una conexión entre los supuestos miembros muertos, vivos y aún no nacidos de una comunidad humana. ${ }^{78}$ Empero, estimo que tal caracterización no alcanza a referir la particularidad ideológica de dicha "fabricación”; algo que, en cambio, sí permite el concepto de mito formulado hacia mediados del siglo xx por Georges Dumezil y reivindicado en años recientes por mitólogos como Bruce Lincoln. ${ }^{79}$ En su célebre tratado sobre el dios nórdico Loki, el historiador de las religiones lanzó la siguiente afirmación: "La mitología precede, frecuentemente prepara, y en todo caso sustituye a la ideología y proporciona los mismos servicios". ${ }^{80}$ Básicamente lo que Dumezil prefiguraba con esta sentencia era su teoría - desarrollada con amplitud en Mito y epopeya (1968-1973) - relativa a que el mito, en tanto que discurso narrativo constituido por imágenes que forman relaciones de subordinación y coordinación - jerárquicas y categóricas-, no se encuentra determinado únicamente por la gramática y la sintaxis de una lengua, sino también, como lo había señalado Émile Durkheim, por el entorno social, por las formas establecidas de organización social y por los ideales que se tenían sobre lo que debería ser aquélla. El mito, visto desde esa perspectiva, no sería otra cosa sino "ideología en forma narrativa": la expresión simbólica de realidades e ideales sociales y culturales. ${ }^{81}$ Otro tanto podría decirse de la historiografía nacional decimonónica, aun sin abstraer el sustrato crítico sobre el cual está construida: que es mito; que es "ideología en forma narrativa”; que expresa una jerarquización

${ }^{78}$ Anderson, Comunidades imaginadas..., 23-29.

${ }^{79}$ Bruce Lincoln, Theorizing Myth. Narrative, Ideology, and Scholarship (Chicago: The University of Chicago Press, 1999), 146-147.

${ }^{80}$ Georges Dumezil, Loki (París: Le Monde-Flamarion, 2010), 233.

${ }^{81}$ Dumezil, Loki, 42; Lincoln, Theorizing Myth..., 147. 
y categorización de eventos en función del lugar social y de los ideales político-sociales defendidos por quien la escribió.

Para sustentar estas afirmaciones, aduzco como pruebas los análisis aquí realizados de las historias nacionales de Herculano y Alamán. En términos generales, dichos análisis hacen explícito cómo en la estructura narrativa de un conjunto de trabajos historiográficos que hicieron de un mismo evento - los descubrimientos y conquistas de ultramar protagonizados por portugueses y castellanos- su eje organizador se despliegan simbólicamente las concepciones ideológicas de cada uno de los autores. Uno de los aspectos más interesantes del fenómeno es que en ningún caso los principios ideológicos son mencionados explícitamente, sino que aparecen más bien sugeridos - simbolizados- por las decisiones narrativas tomadas en cada caso. Así, por ejemplo, es posible reconocer que si Herculano confirió a la segunda década del siglo XVI, al inicio de la empresa ultramarina e imperial lusa, la calidad de término, hiato o cese de la historia nacional, lo hizo porque, desde su perspectiva municipalista y federalista, pretendía deslegitimar los discursos de los centralistas de su tiempo, detentores del poder político, los cuales tenían aún al mencionado acontecimiento como el parteaguas de la "Edad de oro" imperial portuguesa, mientras él no lo podía concebir sino como una interrupción de la multisecular misión libertaria -municipalista - del pueblo portugués. Por otro lado, puede asimismo estimarse que si Alamán valoró a la Conquista, y en particular, a la fundación del ayuntamiento de la Villa Rica de la Vera Cruz a instancias de Hernán Cortés, como el origen del carácter nacional de México, lo hizo, en primer lugar, para contrarrestar las interpretaciones de algunos contemporáneos suyos - liberales y demócratas radicales- quienes, para fundar su idea de la soberanía popular, remontaban la historia nacional mexicana hacia el pasado indígena, concibiéndose como herederos de los pueblos conquistados y defensores de sus derechos soberanos usurpados por los españoles; y en segundo lugar, para dar una base histórica, un origen prestigioso, a su plan de constituir a la sociedad mexicana como un Estado - monárquico o republicano-con un sistema político-administrativo centralista, sí, pero fundado en una red simétrica de municipios federados.

Concluyo este artículo simplemente señalando que este fenómeno de simbolización de principios ideológicos a través de las decisiones narrativas de incipit y excipit no es exclusivo de la historiografía nacionalista decimonónica. Por el contrario, se trata de un fenómeno que priva hasta nuestros días, quiero decir, que no es extraño a los discursos de la historia-ciencia 
de los siglos Xx y xxi. En tanto que escritos buena parte de estos últimos en el marco de metanarraciones de la historia nacional, de la historia atlántica, hemisférica, o incluso, mundial, no sería aventurado afirmar que sus decisiones de comienzo y cierre simbolizan también principios ideológicos. Piénsese, por ejemplo, en el caso de Fernand Braudel, quien - como lo ha mostrado Jacques Rancière- concluyó El Mediterráneo señalando la insignificancia de la muerte de Felipe II, un hombre de cuya pluma "no salen nunca ideas generales o grandes planes", que nada sabía de "verdadera geografía", ${ }^{82}$ porque simbólicamente estaba defendiendo una noción, anclada en presuposiciones ideológicas de que la historia avanzaba de Oriente a Occidente, del Mediterráneo al Atlántico, de las sociedades aristocráticas a las sociedades democráticas; en pocas palabras, desde un mundo donde las que importaban eran las acciones políticas de los grandes personajes, hacia uno donde éstas eran consideradas como la espuma insustancial del mar inmenso de las estructuras geográficas, económicas y sociales. ${ }^{83} \mathrm{~A}$ la luz de estos apuntes, estimo que valdría la pena continuar reflexionando acerca de los condicionamientos ideológicos de las decisiones narrativas que tomamos siempre que escribimos historia.

\section{BiBLIOGRAFÍA}

Alamán, Lucas. Disertaciones sobre la historia de la República Mejicana: desde la época de la conquista que los españoles hicieron, a fines del siglo XV y principios del XVI, de las islas y continente americano, hasta la independencia. 3 v. México: Imprenta de D. José Mariano Lara, 1844-1849.

Alamán, Lucas. Examen imparcial de la administración de Bustamante. México: Consejo Nacional para la Cultura y las Artes, 2008.

Alamán, Lucas. Historia de México. Desde los primeros movimientos que prepararon su independencia en el año de 1808 hasta la época presente. 5 v. 4a. ed. México: Jus, 1942.

Anderson, Benedict. Comunidades imaginadas. Reflexiones sobre el origen y la difusión del nacionalismo. México: Fondo de Cultura Económica, 1993.

Ankersmit, Frank. La experiencia histórica sublime. México: Universidad Iberoamericana, 2010.

${ }^{82}$ Fernand Braudel, El Mediterráneo y el mundo mediterráneo en la época de Felipe II, v. 2 (México: Fondo de Cultura Económica, 1976), 785-786.

${ }^{83}$ Rancière, Les mots de l'histoire..., 23-44. 
Ankersmit, Frank. Historia y antropología. Ascenso y caída de la metáfora. México: Fondo de Cultura Económica, 2004.

Ankersmit, Frank. Narrative Logic. La Haya: Martinus Nijhoff Publishers, 1983.

Berger, Stefan, Mark Donovan y Kevin Passmore. Writing National Histories. Western Europe Since 1800. Nueva York: Routledge, 1999.

Betancourt Mendieta, Alexander. América Latina: cultura letrada y escritura de la historia. México: Anthropos Editorial/Universidad Autónoma de San Luis Potosí, Facultad de Ciencias Sociales y Humanidades, 2018.

Braudel, Fernand. El Mediterráneo y el mundo mediterráneo en la época de Felipe II. 2 v. 2a. ed. México: Fondo de Cultura Económica, 1976.

Bull, Malcolm, comp. La teoría del apocalipsis y de los fines del mundo. México: Fondo de Cultura Económica, 1998.

Burke, Edmund. Reflections on the Revolution in France and other Writings. Nueva York: Everyman's Library, 2015.

Buve, Raymond. "Los municipios y el difícil proceso de formación de la nación en el siglo xix. Algunas reflexiones sobre Tlaxcala.” En Nación y municipio en México, siglos XIX y XX, coordinación de Sergio Miranda Pacheco, 19-54. México: Universidad Nacional Autónoma de México, Instituto de Investigaciones Históricas, 2012.

Catroga, Fernando. A geografia dos afectos pátrios. As reformas político-administrativas (séc. XIX-XX). Coimbra: Edições Almedina, 2014.

Constant, Benjamin. Écrits politiques. París: Gallimard, 1997.

Costeloe, Michael P. La república central en México, 1835-1846. "Hombres de bien" en la época de Santa Anna. México: Fondo de Cultura Económica, 2000.

Dumezil, Georges. Loki. París: Le Monde-Flamarion, 2010.

Fowler, William y Humberto Morales Moreno, coords. El conservadurismo mexicano en el siglo XIX (1810-1910). Puebla: Benemérita Universidad Autónoma de Puebla, 1999.

García Cantú, Gastón, comp. El pensamiento de la reacción mexicana: historia documental, 1810-1962. México: Empresas Editoriales, 1965.

Geary, Patrick J. The Myth of Nations. The Medieval Origins of Europe. Nueva Jersey: Princeton University Press, 2002.

Gellner, Ernest. Nations and Nationalism. Nueva York: Blackwell Publishing, 2006. Hale, Charles. El liberalismo mexicano en la época de Mora (1821-1853). México: Siglo XXI, 1972.

Herculano, Alexandre. "Apontamentos para a história dos bens da Coroa e dos foraes" [1843-1844]. En Opúsculos. V. 6, 193-322. Lisboa: Viuva Bertrand \& Ca., 1884. Herculano, Alexandre. "Carta aos Eleitores de Sintra" [1858]. En Opúsculos. V. 2, 222-242. Lisboa: Viuva Bertrand \& Ca., 1873. 
Herculano, Alexandre. "Cartas sobre a história de Portugal." En Opúsculos. V. 5, 31-160. Lisboa: Viuva Bertrand \& Ca., 1886.

Herculano, Alexandre. História da origem e estabelecimento da Inquisição em Portugal. 3 v. Amadora: Livraria Bertrand, 1975.

Herculano, Alexandre. História de Portugal. Desde o começo da Monarquia até ao fim do Reinado de Afonso III. 2 v. Lisboa: Bertrand, 2007.

Herculano, Alexandre. "Mousinho da Silveira” [1856]. En Opúsculos. V. 2, 167-221. Lisboa: Viuva Bertrand \& Ca., 1873.

Herculano, Alexandre. "Os Vínculos” [1856]. En Opúsculos. V. 4, 2-104. Lisboa: Viuva Bertrand \& Ca., 1879.

Hobsbawm, Eric. Naciones y nacionalismo desde 1780. Barcelona: Crítica, 2012.

Kermode, Frank, The Sense of an Ending. Studies in the Theory of Fiction. Nueva York: Oxford University Press, 1968.

Lincoln, Bruce. Theorizing Myth. Narrative, Ideology, and Scholarship. Chicago: The University of Chicago Press, 1999.

Lourenço, Eduardo. Portugal como destino seguido da Mitologia da saudade. 5a. ed. Lisboa: Gradiva, 2012.

Lungo, Andrea del. L’incipit romanesque. París: Éditions du Seuil, 2003.

Mier, Servando Teresa de. Obras completas. V. 4, La formación de un republicano. México: Universidad Nacional Autónoma de México, 1988.

Mink, Louis O. Historical Understanding. Ithaca: Cornell University Press, 1987.

Noriega, Alfonso. El pensamiento conservador y el conservadurismo mexicano. $2 \mathrm{v}$. México: Universidad Nacional Autónoma de México, Instituto de Investigaciones Jurídicas, 1972.

Palti, Elías. "Lucas Alamán y la involución política del pueblo mexicano. ¿Las ideas conservadoras 'fuera de lugar'?” En Conservadurismo y derechas en la historia de México, v. 1, coordinación de Erika Pani, 300-323. México: Fondo de Cultura Económica/Consejo Nacional para la Cultura y las Artes, 2009.

Palti, Elías. La nación como problema. Los historiadores y la "cuestión nacional”. Buenos Aires: Fondo de Cultura Económica, 2003.

Plasencia de la Parra, Enrique. "Lucas Alamán.” En Historiografía mexicana. V. 3, El surgimiento de la historiografía nacional, coordinación de Virginia Guedea, 307-348. México: Universidad Nacional Autónoma de México, 1997.

Rancière, Jacques. Les mots de l'histoire. Essai de poétique du savoir. Lonrai: Éditions du Seuil, 1992.

Ranke, Leopold von, "Über die Verwandschaft und den Unterschied des Historie und der Politik.” En Sämtiliche Werke. V. 24, 280-293. Leipzig: Duncker und Humblot, 1872. 
Reyes Heroles, Jesús. El liberalismo Mexicano. 3 v. México: Fondo de Cultura Económica, 1974.

Ricoeur, Paul. Temps et récit. 3 v. Lonrai: Éditions du Seuil, 1983.

Rosanvallon, Pierre. El momento Guizot. El liberalismo doctrinario entre la Restauración y la Revolución de 1848. Buenos Aires: Biblos, 2015.

Said, Edward W. Beginnings. Intention \& Method. Nueva York: Columbia University Press, 1975.

Saraiva, José. Herculano desconhecido. 2a. ed. Povoa de Varzim: Publicações Europa-América, 1971.

Serrão, Joaquim Veríssimo. A historiografia portuguesa. Doutrina e crítica. 3 v. Lisboa: Verbo, 1972.

Simon, Joshua. The Ideology of Creole Revolution. Imperialism and Independence in American and Latin American Political Thought. Nueva York: Cambridge University Press, 2017.

Thierry, Augustin. Lettres sur l'histoire de France. 7a. ed. París: Just Tessier Librarie-Editeur, 1842.

Tocqueville, Alexis de. De la démocratie en Amerique. 2 v. París: Éditions Gallimard, 1986.

Vázquez García, Francisco. Estudios de teoría y metodología del saber histórico. Cádiz: Universidad de Cádiz, Servicio de Publicaciones, 1989.

White, Hayden. The Content of the Form: Narrative Discourse and Historical Representation. Baltimore: Johns Hopkins University, 1987.

Zavala, Lorenzo de. Obras. Ensayo crítico [sic] de las revoluciones de México desde 1808 hasta 1830. México: Porrúa, 1969.

\section{SOBRE EL AUTOR}

Doctor en Historia por la Universidad Nacional Autónoma de México. Es profesor de asignatura del Colegio de Historia de la Facultad de Filosofía y Letras de la UNAM y becario posdoctoral del Instituto de Investigaciones Filológicas de la misma universidad. Sus principales líneas de investigación son la historiografía iberoamericana decimonónica y la novela histórica luso-brasileña. Es autor de los artículos “'Accidental Nations,' 'Nations in the Making': James Bryce's Colonialist Interpretation of Latin American Nations", Terrae Incognitae 52, 1 (2020); e "Historia, conocimiento y narración: las 'crónicas-romances' de Alexandre Herculano”, Revista de Estudos Literários 9 (2019). 